\title{
Dissolution and precipitation of carbonate is one mechanism regulating riverine $\mathrm{CO2}$
}

\author{
SHILU WANG ${ }^{1}$
}

${ }^{1}$ The State Key Laboratory of Environmeantal Geochemistry, Chinese Academy of Sciences, Guiyang, Guizhou, 550081, P.R.China (wangshilu@vip.skleg.cn)

Rivers play important roles in the global carbon cycle by delivering a considerable amount of organic and inorganic carbon from land to ocean and emitting $\mathrm{CO} 2$ into the atmosphere. However, little is known about origins of river carbon and processes of production and emission of river $\mathrm{CO} 2$. In this study, we measured the concentrations and carbon isotope of dissolved inorganic carbon (DIC) and $\mathrm{CO} 2$ efflux in the river and the cascade reservoirs along the Lancangjiang River from the source at high altitude of the Tibet Plateau to the downstream. The results indicate that a substantial portion of $\mathrm{CO} 2$ in the river is produced by carbonate precipitation owing to supersaturation, meanwhile in certain waters, carbonate dissolution is one of mechanism of $\mathrm{CO} 2$ consumptions. Thus, it is concluded that precipitation and dissolution of carbonate is an important buffering mechanism to regulate $\mathrm{CO} 2$ concentration in rivers. 